\title{
A música e o verso livre em Manuel Bandeira
}

\author{
Maryllu de Oliveira Caixêta ${ }^{1}$
}

RESUMO: Esse artigo trata do poema "Noturno da rua da Lapa" de Manuel Bandeira. A princípio, abordaremos o aspecto da musicalidade por que visamos algumas mudanças na obra de Bandeira desde a herança romântico-simbolista até a modernidade do verso livre. Nossa hipótese é de que o ritmo do verso livre, em Bandeira, ultrapassa o essencialismo para aderir, em alguns casos, à forma musical, a exemplo do noturno.

ABSTRACT: This article aims at discussing the poem "Noturno da rua da Lapa" by Manuel Bandeira. It is firstly approached the musicality of the poem, once its heritage is perceived as originally inherited from the Romantic-Symbolist tradition, which still remains in the free verse of the Modernist School. One considers the hypothesis that the free verse rhythm in Bandeira surpasses the essentialism in order to meet and represent, in certain cases, musical forms such as the nocturne.

PALAVRAS-CHAVE: Musicalidade; Materialismo; Transcendência KEYWORDS: Musicality; Materialistic; Transcendental conception

\section{O corpo alumbrado}

Nos termos de Antonio Candido e Gilda de Mello e Souza, a poesia de Manuel Bandeira pressupõe uma concepção de "Arte" que adere ao real por meio de uma "deformação voluntária" desse real. Esse processo de adesão e modificação da vida por "antagonismos de método" conta com a encenação de "um Eu que se revela" combinando "certo tipo de materialismo" no nível temático a "uma espécie de transcendência" que

1 Doutoranda em Estudos Literários pela Universidade Estadual Paulista Júlio de Mesquita Filho (UNESP - Araraquara), pesquisa "A ironia nas Terceiras estórias tutaméia" sob orientação da Profa. Dra. Sylvia Helena Telarolli de Almeida Leite e coorientação do Prof. Dr. João Adolfo Hansen. Contato: maryllucaixeta@yahoo.com.br 
resulta de uma súbita identificação da interioridade desse eu com o espaço externo (MELLO E SOUZA; CANDIDO, 1993, p. 3). Também reconhecendo na poesia de Bandeira uma forte relação entre arte e vida, Arrigucci entende a lírica do bardo como paradoxo da "simplicidade que entranha a complexidade e depura a dificuldade em translucidez". Esse paradoxo associa-se à "experiência poética" do alumbramento por que o corpo, "raiz materialista da inspiração", experimenta um "momento de plenitude" no qual níveis correspondentes aos que constituem o espaço entre o real e o sonho são processados na unidade da forma (ARRIGUCCI, 1990, p. 123, 126-129, 133 e 134). Bandeira atualiza o clichê romântico da poesia como transcendência experimentada pelo sujeito poético que estaria incumbido de expressá-la elegendo grandes temas e ideais ao fechar o foco temático no "humilde cotidiano", ampliar a investigação formal e fazer o eu lírico contíguo ao espaço, como no poema "Noturno da rua da Lapa". Nesse artigo, investigamos no poema supracitado um logro recorrente na poesia de Bandeira: o eu lírico relata uma experiência de alumbramento que fornece ao leitor expectativas de sagração do mundo que o preparam para uma experiência estética sensualmente calibrada. Em "Noturno da rua da Lapa", o eu- lírico relata ter testemunhado um fato insólito e inverte um lugar comum metafísico ao sobrevalorizar o corpo em relação ao espírito. A análise que propomos procura verificar o tema da transcendência como valorização da experiência com a matéria também verificável na primazia da forma como materialidade do discurso poético. Passaremos pelo poema "Momento num café" de Estrela da manhã e o compararemos ao poema "Noturno da rua da Lapa" de Libertinagem.

Em sua autobiografia poética intitulada Itinerário de Pasárgada, Bandeira associa a "memória de uma vida" a certa "teoria assistemática" que rege a "técnica do verso" por uma inspiração aleatória. O bardo se auto-intitula "poeta menor" julgando-se inspirado por "iluminação profana" e declara que a poesia resulta de um "instante de alumbramento" (ARRIGUCCI, p. 124-125). A inspiração e a poesia 
que ilumina o espírito tornam-se temas recorrentes nos poemas e nas declarações de Bandeira que assim se alinha à tradição romântica e mais especificamente à vertente simbolista de formação do poeta. Combinadas à concepção moderna de que a poesia "está nas palavras, se faz com palavras" (ARRIGUCCI, p. 130-131), declarações do autor reforçam a plausibilidade da temática do transe na paixão experimentada como poesia. O poeta se fez personagem ao indicar em seus escritos "elementos de sua psicologia individual" como motivos de sua voz ou "personalidade literária” (MELLO E SOUZA; CANDIDO, p. 7). Frequentemente, a crítica menciona a condição trágica do poeta tuberculoso que dedicou a vida à escrita, à leitura, ao estudo e apreciação da arte, o que teria compensado a impossibilidade de tornarse arquiteto, como desejara seu pai. Se "Vou-me embora pra Pasárgada" fixou-se na imagem que temos de poesia às vezes reduzida à evasão sincera ao invés de uma brincadeira com ela, precisamos nos lembrar, por exemplo, de "Momento num café" e do "Noturno da Rua da Lapa".

\section{MOMENTO NUM CAFÉ}

Quando o enterro passou

Os homens que se achavam no café Tiraram o chapéu maquinalmente

Saudavam o morto distraídos

Estavam todos voltados para a vida

Absortos na vida

Confiantes na vida.

Um no entanto se descobriu num gesto largo e demorado Olhando o esquife longamente.

Este sabia que a vida é uma agitação feroz e sem finalidade Que a vida é traição

E saudava a matéria que passava

Liberta para sempre da alma extinta.

(BANDEIRA, 1993, p. 141)

A vida trai a matéria do corpo subjugado pela alma. É o corpo quem se livra da alma extinta na ótica do eu-lírico empático ao observador que se descobre ou se ilumina tirando o chapéu "num gesto largo e demorado" ante o cortejo, no que se distingue dos demais que o 
fazem "maquinalmente". O poema denuncia o mecanicismo da vida moderna ao repetir a palavra "vida", o que a esvazia enquanto a morte do outro pouco altera o ritmo automatizado dos homens do "café" que tanto pode designar a bebida estimulante que resulta do fruto do cafeeiro como o estabelecimento comercial tipicamente urbano onde o servem. A poesia reverte o embotamento dos sentidos resultante do ritmo maquinal da vida urbana na qual o homem está tão voltado para a vida, absorto e confiante nela que não percebe que é "traição", "agitação feroz e sem finalidade". Se a matéria do corpo morto que passa lentamente se desvaloriza em contraste com o ritmo da vida moderna, o poeta revaloriza o corpo como médium da "experiência do momentâneo" sentida como poesia (ARRIGUCCI, p. 128), numa concepção vitalícia de poesia combinada à linguagem e ao vocabulário cotidianos. O poema simula o ritmo da linguagem cotidiana recorrendo ao verso livre determinante de uma musicalidade que destoava das expectativas dos leitores de então acostumados ao beletrismo que estetizava fórmulas simbolistas.

A busca da simplicidade quase popular, em Ritmo dissoluto, ajudaria este pendor, que domina a partir de Libertinagem, apurado e completado pela capacidade de pôr fora o acessório. O poeta que então se confirma não apenas discerne o nervo da realidade, mas sabe despi-lo dos adornos coloridos e melodiosos que, nos primeiros livros, dispersavam o impacto sobre o leitor. A essa altura, amadurece nele o que se poderia chamar de senso do momento poético - o tato infalivel para discernir o que há de poesia virtual na cena e no instante, bem como o poder de comunicar essa iluminação. (MELLO E SOUZA; CANDIDO, p. 5)

\section{A música}

Ao adotar o verso livre e depurar a musicalidade de herança simbolista, o poeta opta por uma poética paródica do sentimentalismo e do lugar comum de extração metafísica. O verso livre apropria-se da temática do alumbramento que caracteriza o artista romântico como alguém que estranha e se maravilha com o mundo, razão pela qual 
rejeitou a ilusão da forma fixa adotada pelos que supunham nela uma receita de poesia. O verso livre em Bandeira indica uma nova concepção de ritmo e não o abandono do ritmo em favor da expressão. O poeta afirma que o valor da musicalidade fundamenta a concepção de sua poesia como tecido, e não dança. Castro Alves assim como Cruz e Souza servem-lhe como exemplos de sinfonistas. A expressão das ideias e dos sentimentos serviria como "ponto de vista do fundo" e o primeiro plano passa ao domínio da "liberdade de movimentos" de "afinação poética" (BANDEIRA, 1984, p. 75 e 78). O motivo musical é uma constante na obra como na autobiografia poética Itinerário de Pasárgada. Foi o poeta brasileiro mais musicado do século $\mathrm{XX}$, segundo Mariz: "A contribuição do bardo pernambucano à música brasileira foi muito variada e extremamente significativa" (1987, p. 66), tendo atuado, inclusive, como crítico musical nos anos 1920. Nos poemas, citava Debussy, Schubert, Beethoven e também modinhas ou cantigas de tradição oral, trazidas de memória da infância. Menciona em seus poemas gêneros musicais como "cantigas, cantilenas, madrigais, modinhas, rondós" (MARIZ, p. 67). Chega a dar exemplos de como a frase musical adere-se completamente ao texto que a antecede em musicalidade e poderia mesmo substituir-se por muitas outras frases musicais, pois os textos são fontes de muitas melodias. Os exemplos são o Du bist die Ruth, de Schubert e o Ich liebe dich, sowie du mich, do lied de Beethoven. Cita Mário de Andrade para argumentar que a música é uma escrava da palavra. Escreveu o poema "Azulão" para uma melodia de Jaime Ovalle que depois foi também musicado por Camargo Guarnieri e, ainda, por Radamés Gnattali. Depois, seu "Cantiga" foi musicado diferentemente por Guarnieri e posteriormente por Lorenzo Fernandez (BANDEIRA, 1984, p. 79), para citar alguns poucos exemplos. As influências extraliterárias foram inúmeras como, além da já mencionada experiência de alumbramento, as artes do desenho, da pintura e, principalmente da música. 
Maior ainda foi em mim a influência da música. Não há nada no mundo de que eu goste mais do que de música. Sinto que na música é que conseguiria exprimir-me completamente. (...) Por volta de 1912, tempo em que andei me intrometendo na música e até ousei querer entender o Tratado de Composição de Vincent d'Indy, tentei, muito sugestionado pelo livro de Blanche Selva sobre a Sonata, reproduzir num longo poema a estrutura da forma sonata. (...) Não foi simples exercício: era expressão de uma profunda crise de sentimento: só que eu, como corretivo ao possível sentimentalismo, desejei estruturar os meus versos (eram versos livres) segundo a severa arquitetura musical. (BANDEIRA, 1984, p. 49-50)

Sendo o "Noturno da rua da Lapa" poema de Libertinagem, obra de 1930, podemos considerar que nas quase duas décadas anteriores o poeta manteve em seu horizonte o exercício de ritmos inspirados pela arquitetura musical. Nesse poema que apresenta a imagem de um "caso que se passou com [o músico] Ovalle", o poeta granjeou a "conquista difícil" que foi para ele o verso livre (BANDEIRA, 1984, p. 44 e 91).

Bandeira incorpora concepções estéticas da música à palavra poética entendendo-a como imagem. A esse respeito, declarou que “dizer que um verso canta é falar por imagem" (BANDEIRA, 1984, p. 79). O recurso da imagem resolveu as dificuldades de identificar o verso livre ao ritmo do que o poeta concebia como experiência poética do alumbramento. O poeta seleciona nos eventos cotidianos parte dos elementos com que compõe as imagens. Desse modo, o verso livre desvincula-se do essencialismo deduzido do culto da expressividade. $O$ ritmo irregular e dissonante do verso livre expressa o da vida moderna aproximando, por uma escolha formal, a poesia e a experiência. O bardo depurou a musicalidade com proveito da paixão, aproveitando-as dentro da concepção moderna de poesia que privilegia a palavra, a paródia e o humor. A própria palavra, assim como o corpo, são materialidades que dão sentido e possibilidade à experiência. De modo geral, para os modernistas, o "estilo" era uma questão problemática: a "procura da poesia, a luta vã com as palavras, a ironia, o senso 
paródico, os riscos do impasse e do silêncio". Diferenciando-se da retórica clássica, o discurso humilde de Bandeira assume uma "dicção límpida e aparentemente fácil" de "lírico intratável" (ARRIGUCCI, p. 129). A procura da poesia entrevista na obra de Bandeira elabora, tematiza e oferece como imagem a experiência poética do alumbramento. $\mathrm{O}$ anedótico se desenvolve para formar a imagem. Em alguns casos, como o do poema "Noturno da rua da Lapa", a narração do evento cotidiano e o parágrafo ao invés do verso rompem com a diç̧ão elevada da poesia tradicional e a atualizam vinculando-a a experiência do homem do século XX.

\section{NOTURNO DA RUA DA LAPA}

A janela estava aberta. Para o quê não sei, mas o que entrava era o vento dos lupanares, de mistura com o eco que se partia nas curvas cicloidais, e fragmentos do hino da bandeira.

Não posso atinar no que eu fazia: se meditava, se morria de espanto ou se vinha de muito longe.

Nesse momento (oh! por que precisamente nesse momento?...) é que penetrou no quarto o bicho que voava, o articulado implacável, implacável!

Compreendi desde logo não haver possibilidade de alguma evasão. Nascer de novo também não adiantava. - A bomba de flit! pensei comigo, é um inseto!

Quando o jacto fumigatório partiu, nada mudou em mim; os sinos da redenção continuaram em silêncio; nenhuma porta se abriu nem fechou. Mas o monstruoso animal FICOU MAIOR. Senti que ele não morreria nunca mais, nem sairia, conquanto não houvesse no aposento nenhum busto de Palas, nem na minh'alma, o que é pior, a recordação persistente de alguma extinta Lenora. (BANDEIRA, 1993, p.141)

A paráfrase pode ser: o lírico encontra-se disperso no quarto quando entra pela janela um inseto. Ele recorre a uma bomba de flit para resolver o problema e subitamente compreende a impossibilidade de evasão e renascimento. No último movimento desse noturno, o animal fica maior, imortal e instala-se permanentemente no quarto. Neste poema, o ritmo do verso identifica-o ao da prosa no parágrafo, o eu-lírico simula parcialmente a voz de um narrador, o 
espaço externo do quarto com a janela aberta corresponde ao interno e ao emocional, a anedota forma imagem e o prosaísmo de um termo como flit mistura-se ao preciosismo de uma referência clássica como "Palas Atenas" e ao vocábulo "lupanares" recorrente na poesia romântica. Cada um desses elementos concorre para os efeitos simultâneos de estranheza e humor do poema. O recurso do humor funciona como "estratégia intelectual diluente da emoção de herança romântica” (BRAYNER, 1987, p. 46). Do ritmo já procuramos tratar quando discutimos a depuração da musicalidade de herança simbolista em direção ao verso livre inspirado na forma musical, nesse caso o "noturno". Composição de caráter terno e melancólico muito em voga no século XIX, o noturno apresenta compassos irregulares como os parágrafos do poema, as tensões não se resolvem e prolongam-se, há pequenas dissonâncias que no poema decorrem de vocábulos e expressões vulgares como flit e "jacto fumigatório". No poema, a melancolia combina-se à paródia que serve como antídoto ao sentimentalismo, o clímax pouco se destaca e os conflitos permanecem sem justificação razoável no nível da anedota. O prolongamento das tensões torna seus limites imprecisos e coincide com a dissolução do narrador lírico cuja consciência não domina os mínimos eventos que se passam no quarto e o absorvem. "A janela estava aberta. Para o quê não sei (...)". "Não posso atinar no que eu fazia (...)". O humor do conflito deve-se a sua aparente irrelevância que recebe um tratamento dramático: "penetrou no quarto o bicho que voava, o articulado implacável, implacável!". Segue-se a essa agitação provocada pelo pequeno inseto uma revelação instantânea, no parágrafo seguinte, que resulta da formação de consciência que ilumina o narrador lírico até então disperso. Conclui a impossibilidade de evasão e muda da atividade contemplativa para o combate. O conflito se materializa graças ao inseto que torna possivel que após a dispersão lenta e introspectiva dos três primeiros parágrafos o lírico identifique uma causa para o incômodo e disponha-se a solucioná-lo. “- A bomba de flit! pensei comigo, é um inseto!". O alumbramento coincide com o clímax humilde 
de noturno no movimento final que retoma o ritmo interno correspondente ao externo dos primeiros parágrafos, mas de outro modo, pois se segue ao conflito revelado a suspensão do combate. "Mas o monstruoso animal FICOU MAIOR". Depois do clímax, o conflito identificado ao inseto transforma-se subitamente em uma causa material insólita e mutante, marcada em caixa alta. Segue-se um sentimento que parece articular a dispersão inicial. Podemos nos lembrar, acerca do que já dissemos sobre o poema "Momento num café", que o comportamento maquinal embota a sensibilidade do homem moderno, mas alguns não conseguem adaptar-se conservando o gesto largo e lento da contemplação. O lírico termina o poema com um sentimento sem razoabilidade e de caracterização paródica: a inexistência do "busto de Palas" e "nem na minh'alma, o que é pior, a recordação persistente de alguma extinta Lenora”. A temática da eternidade e da permanência da poesia se atualiza na recusa da harmonia clássica que pressupunha a estabilidade do saber cada vez mais incompativel com a vida na cidade moderna. A dimensão trágica no tratamento da temática amorosa pelos românticos é retomada com nostalgia ao ser desvinculada da experiência moderna esvaziada de sentido. A poesia daquele instante depende da importância central que a importunação do inseto assume na anedota de um evento cotidiano afetado pelos ruídos da rua da Lapa frequentada pelas prostitutas dos "lupanares". O inseto como metonímia da natureza dá corpo ao conflito parodístico da beleza harmônica do busto de Palas produzido por uma concepção clássica da arte como mimese da natureza perfeita. O mundo moderno parece imperfeito ao poeta que recusa se adaptar e produz a forma expressiva desse descompasso. O poeta coloca em discussão o gênero poema ao optar pela forma do parágrafo para narrar acontecimentos desenvolvidos no espaço específico do quarto representado como continuação de seu estado de espírito. Confiamos que se trata de um poema porque além de pertencer a um livro de poemas com assinatura de um poeta consagrado, admite rasgos líricos no terceiro parágrafo, o desfecho insólito culmina na eternidade do 
inseto monstruoso que remete às tradições poéticas clássica e romântica referidas por meio do busto de Palas e da Lenora de Poe. Não há harmonia no mundo moderno, os ruídos e zumbidos ajudam a compor a música fragmentária do cotidiano e da intimidade.

A perspectiva do lírico conduz a narração e conclui a anedota manifestando consciência de um sentimento: o da imortalidade do monstruoso animal. A modernidade da poesia de Bandeira inclui o evento cotidiano como ponto de partida da experiência poética, a aceitação tácita do extraordinário, alusões à tendência evasiva e a estados semelhantes aos de sonho, a explosão lírica como a estilizada no terceiro parágrafo, a melancolia de negar a evasão enquanto afirma a falta de outra vida ou de redenção, o humor e a paródia. No primeiro parágrafo, o ouvido urbano aparece isolado em um contexto de íntima dispersão no quarto com a janela aberta por onde recebe estímulos sonoros fragmentados como numa figura cubista; depois, a dissolução das identidades das coisas e do espaço contínuo ao lírico, a negação do outro mundo, a autonomia do invento poético retomado no diálogo com as tradições. O conflito desestabilizador da situação inarticulada inicial forma no lírico a consciência da necessidade de agir e enfrentar o articulado implacável que depois reconhecerá como sendo o inseto. Se terminasse aí, o poema caracterizaria a atividade contemplativa como insustentável e a subordinaria à ação guiada pela razão instrumental ilustrada na ação de recorrer à bomba de flit para eliminar o conflito. No entanto, o último parágrafo retoma e amplia a desarticulação inicial. O jato fumigatório, os sinos da redenção e o inseto já visto como monstruoso animal que "FICOU MAIOR" assumem a posição ativa enquanto o lírico volta a mostrar-se permeável ao espaço exterior e a sentir o conflito atribuindo-o a causas imaginárias que servem como referências às tradições clássica e romântica. Ao aceitar com melancólica naturalidade a fusão do espaço íntimo com o do quarto que inclui o inseto monstruoso, o lírico alude a Kafka e afirma a imortalidade do inseto ou do tipo de ficção de Kafka que parece partir de um pesadelo ampliado na ausência de sentido que rejeita a 
harmonia natural clássica sem poder apoiar-se na subjetividade romântica que correlacionava as unidades da alma e do amor. Mesmo sendo monstruosa aparição antinatural que compõe a experiência daquele que se vê diluído no mundo, o inseto kafkaesco além de imortal também é articulado e, portanto, inteligivel. As representações do conflito humano, entendido como o estar no mundo, passam a pressupor concepções de arte que elaboram e prolongam a reflexão sem aplacar o conflito, mas o imortalizam vinculando-o às tradições com que rompe.

Nas primeiras fases da obra de Bandeira, é notável o relacionamento entre "teoria e práxis em poesia" que as centraliza no "eixo do eu". Na medida em que vai crescendo a consciência poética associada ao apego à vida, estes "é que serão o eixo principal". "O real vivido se faz simbólico" numa linguagem mais rica que a da "expressão das ideias e das emoções” (BRANDÃO, 1987, p. 22). Segundo Brandão, ainda que como um "campo de possibilidades e estímulos", houve um “processo de negação dos valores poéticos do passado" (1987, p. 26), tomando como ponto marcante dessa mudança o poema intitulado "Poética". A posição de Sônia Brayner nos parece mais adequada ao humor presente no diálogo com as tradições nos poemas de Bandeira, pois ele "assume um comportamento de controle, mas não de oposição no combate à ênfase de nosso lirismo tradicional" (BRAYNER, p. 46). A arte interessada na experiência como seu ponto de partida assume a função de estimular novas possibilidades de consciência afastando-a dos discursos oficiais, o que foi muito visado pelas correntes estéticas que se seguiram ao impressionismo. Remetendo a uma expressão de Augusto de Campos, o bardo chegou a caracterizar as sentenças desgastadas das frases de cartilha, a princípio de intensa poesia, como "túmulos da imagem", como informa Haroldo de Campos em seu ensaio sobre Bandeira. Uma vez reconhecida a potencialidade poética do lugar comum anterior à sua cristalização, Bandeira é classificado por Haroldo de Campos como um "desconstelizador" ou um reativador do potencial imagético adormecido pelo lugar comum. O poema constelação de 
Mallarmé, "Un coup de dês”, abole o acaso fugazmente ao desembaraçar as palavras das hierarquias sintáticas, do lugar fixo na página, das relações de causa e efeito. A desconstelização, equivalente ao estranhamento de Schklóvski, faz o percurso contrário obrigando o acaso a lançar dados no lugar comum. Ou seja, ele parte "do lugar comum para o lugar incomum”, segundo expressão de Décio Pignatari (CAMPOS, 1967, p. 100-102). De acordo com esse procedimento, os clichês românticos tornam-se instáveis ao serem parodiados e reativados em sua potencialidade numa nova permuta que reativa o sentido da experiência poética, da imagem orientada por um entendimento da musicalidade e do lirismo associado ao alumbramento.

\section{Referências bibliográficas}

ARRIGUCCI, Davi. A poesia em trânsito: revelação de uma poética. In: Humildade, paixão e morte. São Paulo: Companhia das Letras, 1990, p.123-138.

BANDEIRA, Manuel. Itinerário de Pasárgada. Rio de Janeiro: Nova Fronteira, 1984.

Libertinagem. In: Estrela da vida inteira. Rio de Janeiro: Nova Fronteira, 1993, p.125-144.

BRANDÃO, Roberto de Oliveira. Poética e vida em Bandeira. In: LOPEZ, Telê Porto Ancona (org.). Manuel Bandeira: verso e reverso. São Paulo: T.A. Queiroz, 1987, p.22-28.

BRAYNER, Sônia. O "humour" bandeiriano ou as histórias de um sabonete. In: LOPEZ, Telê Porto Ancona (org.). Manuel Bandeira: verso e reverso. São Paulo: T. A. Queiroz, 1987, p.42-47. 
CAMPOS, Haroldo. Bandeira, o desconstelizador. In: Metalinguagem. Petrópolis: Vozes, 1967, p.99-105.

MARIZ, Vasco. Manuel Bandeira, o poeta e a música. In: LOPEZ, Telê Porto Ancona (org.). Manuel Bandeira: verso e reverso. São Paulo: T. A. Queiroz, 1987, p.65-70.

MELLO E SOUZA; Gilda e CANDIDO, Antonio. Introdução. In: BANDEIRA, Manuel. Estrela da vida inteira. Rio de Janeiro: Nova Fronteira, 1993, p.3-17. 